\title{
O PROJETO INTEGRADOR COMO PRÁTICA DIALÓGICA DE ENSINO E APRENDIZAGEM NA EDUCAÇÃO PROFISSIONAL E TECNOLÓGICA
}

\author{
THE INTEGRATIVE PROJECT AS A DIALOGICAL PRACTICE OF \\ TEACHING AND LEARNING IN PROFESSIONAL AND \\ TECHNOLOGICAL EDUCATION
}

\author{
Lucélia Maria Santos Aragão ${ }^{4}$ \\ Meiriane Rebouças da Silva do Rosário ${ }^{5}$ \\ Luís Gomes de Moura Neto ${ }^{6}$
}

Pensar em práticas dialógicas de ensino na educação profissional e tecnológica, significa compreender antes de tudo, a educação como um caminho de transformação da vida humana e o trabalho como meio de sua realização. Significa refletir acerca das relações que constituem o mundo humano e o seu desenvolvimento no sentido da evolução do homem e da sociedade pois todas as questões que envolvem a educação e suas práticas no âmbito da EPT são idealizadas no campo da coletividade, da comunicação e da força criadora e transformadora dos homens.

A escolha da teorização de Paulo Freire se deu pela importância das suas contribuições, reconhecidas acerca do ensino dialógico como modelo de educação humana e

\footnotetext{
${ }^{4}$ Possui graduação em Secretariado Executivo pela Universidade Federal do Ceará (2003). Especialista em Gestão Pública (2013), discente do Programa de Pós-Graduação em Educação Profissional e TecnológicaPROFEPT/IFRN. Exerce o cargo de Secretária Executiva na Universidade Federal do Ceará. E-mail: aragaolucelia@gmail.com

${ }^{5}$ Possui graduação em Pedagogia pela Universidade do Estado do Rio Grande do Norte (1998). Especialista em Gestão Escolar (PROGESTAO-2004). discente do Programa de Pós-Graduação em Educação Profissional e Tecnológica- PROFEPT/IFRN. Pedagoga no Instituto Federal de Educação, Ciência e Tecnologia do Ceará IFCE. E-mail: meiriane.reboucas@ifce.edu.br

${ }^{6}$ Licenciado em Tecnologia de Alimentos. Mestre em Ciência e Tecnologia dos Alimentos. Doutor em Biotecnologia. Docente do Instituto Federal de Educação, Ciência e Tecnologia de Pernambuco - Campus Afogados da Ingazeira. E-mail: luis.neto@afogados.ifpe.edu.br
} 
transformadora. Outras reflexões que constituem a compreensão da prática de ensino dialógica foram apresentadas com discussões relevantes realizadas por autores que são pilares dessa ação educativa apresentada neste estudo, entre eles, Ciavatta e Frigotto. Neste momento, consideramos essencial, retomar conceitos e concepções centrais da educação profissional e tecnológica, antes de apresentar o projeto integrador como modelo compatível de organização curricular de prática de ensino dialógica.

Este estudo é bibliográfico e documental e se apresenta organizado a partir de três partes, a saber: a primeira, traz a discussão da prática dialógica de ensino na perspectiva de Paulo Freire; a segunda, retoma conceitos e concepções centrais da educação profissional e tecnológica; e a terceira, apresenta o projeto integrador como modelo aplicável de ação de ensino na perspectiva dialógica.

\section{Perspectiva Dialógica Em Paulo Freire}

Para Freire (1980), o diálogo como mediador do conhecimento, tem um papel fundamental no desenvolvimento do mundo humano e social e se constitui como um dos principais meios de construção do saber, portanto, parte da educação, que na visão do autor é "... comunicação, é diálogo, na medida em que não é a transferência de saber, mas um encontro de sujeitos interlocutores que buscam a significação dos significados." (FREIRE, 1980, p. 69).

No pensamento de Freire, educar é ação criadora, humanizadora e transformadora, pautada na ética e na vida e compromissada com o conhecimento construtor da existência humana plena e livre, com a superação de toda opressão e discriminação que desumaniza os sujeitos. Deste modo, um processo educativo que vise essa humanização, deve ser realizado por meio da comunicação ativa, recíproca e cooperativa entre os sujeitos, devendo ser estruturado em práticas educativas que permitam o diálogo.

Assim, a educação é um lugar onde ocorrem as relações de diálogo e a construção de significado do mundo humano, ou seja, lugar de criação humana. Neste sentido, a aquisição do conhecimento na formação dos sujeitos não deve ser uma produção alienada, mas, uma produção criada e recriada na dialogicidade dos homens que falam, ouvem, trocam 
experiências, refletem, criticam, criam e recriam o seu mundo, processo, no qual o saber social e pedagógico dialogam e a práxis humana é desenvolvida.

Uma das ideias centrais do pensamento de Paulo Freire é a compreensão da construção coletiva do desenvolvimento humano e do papel da educação crítica no processo transformador da realidade dos sujeitos e de seu mundo, que somente é possível em uma formação que não se traduza em treinamento técnico e permita nos indivíduos a reflexão e a tomada de consciência. Desta forma, durante sua trajetória, ele criticou o ensino oferecido pela maioria das escolas, qualificando-o de "educação bancária", que reduz o papel da educação ao ato de depositar, onde os educandos são os depositários e o educador o depositante, que concebe ao professor, o papel de detentor do conhecimento, condutor da memorização mecânica do conteúdo por ele narrado aos alunos, seres passivos e sem nenhum saber, cabeças vazias onde o professor deposita o conhecimento. Esse modelo reduz a educação à pura transferência de conteúdo, para o exercício de adaptação ao mundo, em detrimento de posições indagadoras que colaborem com o seu processo de conscientização e mudança.

Em contraposição a esse modelo de educação antidialógica, marcadamente autoritária, que domina e fortalece a divisão entre aluno e professor, entre opressor e oprimido e destrói a curiosidade e criatividade dos sujeitos, Paulo Freire (1987) propõe a concepção de educação baseada no diálogo e na ação transformadora de homens e mulheres sobre suas condições existenciais, que tem como objetivo, o fazer pensar e refletir nos sujeitos, acerca das questões da sua realidade que precisam ser modificadas, por meio da conscientização-ação.

Na concepção de educação dialógica, o educador assume em seu papel, a vocação humanista, com a inclusão em suas técnicas pedagógicas, do redescobrimento do processo histórico de constituição da consciência humana e a construção do processo educativo com base na essência da prática da liberdade como elemento fundamental do mesmo. Outro ponto importante para compreensão dessa concepção, pautada no pensamento Freiriano, é o lugar central que o diálogo ocupa. Para Freire, o diálogo se dá por meio da palavra, sendo a sua expressão um direito e um dever de todos e não um privilégio de alguns.

Continuando a compreensão na linha do pensamento apresentado por Freire, que enfatiza a importância da palavra com ação para não tornar-se mera falácia, ao mesmo 
tempo que sem reflexão, para não tornar-se simples ativismo. Assim, é na palavra, no trabalho e na ação-reflexão, que o homem existe como ser, se pronunciando ao mundo e o modificando, não podendo a palavra ser pronunciada sozinha de forma isolada. Ela deve ser expressa no encontro de homens mediatizados pelo mundo que tem no diálogo o caminho da sua significação.

Desta forma, para que o diálogo ocorra, é necessário a existência de homens que queiram e se permitam dialogar, ato que pressupõe amor ao mundo e aos homens e que deve superar a arrogância pelo exercício da humildade. Assim, não deve existir no diálogo, lugar para ignorantes absolutos e nem sábios absolutos, pois é um local de busca conjunta de saberes. O diálogo deve ser realizado por meio de relações horizontais, que permitam aos sujeitos sairem de si mesmos e abrirem-se ao outro, com fé nos homens, no seu poder de fazer, de criar e de transformar.

$\mathrm{Na}$ prática dialógica de ensino, o professor ao reconhecer a importância da comunicação para o movimento de mudança social assume o papel de desafiador, promovendo a educação como prática de liberdade e consequentemente, desenvolve junto aos alunos a capacidade crítica, de criatividade, respeito, e liberdade. Assim, a construção do conhecimento se dá num processo coletivo onde professor e aluno ensinam e aprendem juntos na direção da leitura crítica da realidade. Estes, por sua vez, são desafiados a compreender criticamente o contexto em que vivem, reconhecendo na educação o papel imprescindível para a transformação consciente e crítica da realidade, que converge para sua libertação e emancipação, sendo, portanto, a aprendizagem um ato revolucionário. Neste sentido o diálogo é a base que conduz todo o processo de uma educação libertária, que busca tornar os sujeitos conscientes de si e do mundo.

A consciência tem um papel fundamental no mundo humano, é por meio dela que o homem age na natureza para transformá-la, criando assim o mundo humano e social. É na consciência que ocorre o processo de subjetivação pelo homem da objetividade do mundo com a codificação e decodificação do conhecimento para a construção de significados, processo esse constituído pelas relações entre homens e outros homens e o seu mundo e tendo a dialogicidade como base intermediadora destas relações humanas.

O homem como ser social existe pelo trabalho, sendo a consciência uma característica determinante da atividade humana e o diálogo a matriz de todo o processo de 
construção do mundo humano, que é criado, recriado e transformados pelos homens enquanto produzem a sua existência.

Nessa perspectiva de desenvolvimento do ser pleno e livre, a educação deve ser transformadora da própria realidade do sujeito, que deve ser visto em sua totalidade, como ser histórico e contextualizado e se constituir numa relação dialógica e no entendimento da indissociabilidade entre teoria e prática, onde educação e trabalho constituem o homem em sua plenitude do ser.

\section{Perspectivas e conceitos das bases conceituais em EPT}

Pensar a educação como práxis humana, é uma perspectiva idealizada por Freire e compartilhada na educação profissional, que tem como base as relações indissociáveis entre ação e reflexão, humanização e educação, teoria e prática, se constituindo um caminho realizável para plena formação humana. Nesse entendimento, a educação deve ser pautada na perspectiva da unidade do homem com o seu mundo, portanto, os conhecimentos técnicos devem ser compreendidos em sua historicidade, com função social e política em um contexto de mundo, no entanto, essa perspectiva sempre foi e ainda é deixada de lado.

Para compreender essa realidade é importante destacar, que o surgimento da educação profissional foi no contexto de desumanização com a expropriação do homem de seu processo trabalho. A mudança na base produtiva econômica da feudal para industrial, trouxe a necessidade de uma formação técnica de trabalhadores para as indústrias, que foi desenvolvida de forma fragmentada e não dialógica, desumana, incapaz de ver o homem como sujeito ativo de sua história, pelo contrário, o pacificou quando realizou a objetivação do homem e de seu trabalho que se tornaram mercadorias. Assim, a educação e a sociedade são resultantes das determinações do modo de produção que dualiza a sociedade em classes, a relação entre teoria e prática, o tipo de educação e o público de acesso (SAVIANI, 2006).

A história do Brasil traz consigo o peso da origem social na trajetória escolar das diferentes classes sociais. Na educação profissional, em especial a técnica de nível médio não é diferente. Considerando-se que, desde o início a EPT foi pensada com o objetivo de treinar uma parcela da população desfavorecida economicamente para desempenhar 
atividades manuais consideradas de nível intelectual inferior, acentuando cada vez mais o dualismo educacional. Seu objetivo principal era formar mão-de-obra para as indústrias e empresas, enquanto a elite estudava para ocupar cargos de natureza intelectual.

Tal prática acabava adaptando o homem à realidade do mercado de trabalho, na qual se aprende o que vai ser útil para o desenvolvimento profissional. Consequentemente, os conteúdos passaram a ser definidos a partir das atividades profissionais que serviam e servem para adaptar os alunos para o mercado de trabalho, sem poder de humanização. Essa concepção de educação profissional tecnicista, pragmática e instrumental, continua presente até hoje nos espaços escolares. Contudo, para Santos (2018, p. 38):

[...] atualmente, não há como pensar em uma educação que apenas prepara os jovens para executar tarefas instrumentais, adestrando-os ou treinando-os para determinadas atividades, mas primordialmente para a partir de uma formação técnica contribuir para a emancipação do sujeito, ou seja, ensinar o saber fazer e também ensiná-lo a ser sujeito ativo, pensante e participativo.

Visando romper com esse formato de educação dual que lida com o conhecimento de forma fragmentada, ganha destaque a ideia de politecnia, como um processo formativo de transformação, baseado no desenvolvimento integral dos sujeitos, em todos os aspectos, com unidade entre trabalho, ciência e cultura. Saviani (2003, p. 136) afirma que "a noção de politecnia se encaminha na direção da superação da dicotomia entre trabalho manual e trabalho intelectual, entre instrução profissional e instrução geral", derivando da problemática do trabalho.

A literatura crítica compreende o trabalho como princípio educativo, visto a natureza formadora do trabalho, pois o homem aprende a ser homem ao longo do processo, e humanizadora da educação ao ser a via para o desenvolvimento humano, é na relação entre trabalho e educação que o homem se desenvolve, sendo essa relação a base desse princípio, deste modo, o aluno deve possuir e dominar ambos os conhecimentos, teóricos e práticos para se tornar uma pessoa completa. Assim, a ideia de politecnia se baseia no resgate do princípio da formação humana em sua totalidade, por meio de um ensino que integre ciência e cultura, humanismo e tecnologia, visando o amplo desenvolvimento de todas as potencialidades humanas. 
Saviani (2003) acrescenta a compreensão, a questão da visão distorcida de politecnia pelo sentido literal da palavra, que significa múltiplas técnicas ou multiplicidade de técnicas, levando ao equívoco o entendimento como, a totalidade das diferentes técnicas fragmentadas, autonomamente consideradas para a preparação de mão de obra. Essa interpretação não corresponde à verdadeira concepção de politecnia, como formação possível no contexto de uma sociedade capitalista que seja travessia para o desenvolvimento de um novo modelo social, que permita uma formação omnilateral, um desenvolvimento humano completo, em todas as suas potencialidades, ou seja, uma formação para existência do ser em sua plenitude, em sua totalidade.

Essa formação voltada para completude do ser, preconizada pelas sociedades socialistas, a politécnica, segundo Ciavatta (2014), não se tem como transpor para a educação no Brasil, por ser dominada pelo capital, onde os jovens das classes populares precisam se inserir no mercado de trabalho, bem antes de concluírem a educação básica. A autora reforça ainda que no Brasil,

[...] As condições de vida são adversas, as relações de trabalho são dominadas pelo poder hegemônico do capital, a educação não está universalizada em acesso e em qualidade para toda a população: a ideologização crescente da educação subsumida ao consumo e ao mercado de trabalho torna ambíguo o conceito de qualidade da educação [...] (CIAVATTA, 2014, p. 197).

Diante da impossibilidade de concretização da politecnia em seu sentido pleno para todos no Brasil, concluiu-se que uma solução transitória e viável, que contém os princípios da sua construção poderia ser concretizada a partir da oferta do Ensino Médio Integrado, com base unitária para todos, contemplando o aprofundamento dos conhecimentos científicos produzidos, sistematizados e acumulados historicamente pela sociedade, bem como, os objetivos adicionais de formação profissional numa visão da integração dessas dimensões. Para Moura (2013, p. 707) “o Ensino Médio Integrado pode ser considerado o germe da formação humana, omnilateral ou politécnica".

Segundo Frigotto, Ciavatta e Ramos (2005, p. 43) "O ensino médio integrado ao ensino técnico, sob uma base unitária de formação geral, é uma condição necessária para se fazer a travessia para uma nova realidade". Eles consideram que o ensino técnico integrado 
ao Ensino Médio, com vistas a uma educação para formação omnilateral, implica numa integração de dimensões fundamentais da vida que estruturam a prática social no processo educativo, a saber: o trabalho, a ciência e a cultura no sentido de formar o ser humano na sua integralidade, seja ela física, mental, cultural, política, científico-tecnológica. Dessa forma,

[...] A primeira dimensão, o trabalho, é compreendido como algo próprio da vida do ser humano que desde o início da humanidade utilizou a racionalidade para transformar a natureza de acordo com as suas necessidades, portanto, possui, nesse sentido, um valor de uso. A ciência é caracterizada como a produção dos conhecimentos desenvolvidos pela humanidade ao longo da história. Por último, a cultura é compreendida como as diversas manifestações artísticas bem como os princípios étnicos que envolvem as normas da sociedade (ALVES, DANTAS, SOUZA, 2019, p. 128).

Nessa perspectiva de integração, o objetivo da formação profissional não se pauta pelos interesses do mercado, mas se constitui numa possibilidade para os estudantes na construção de seus projetos de vida, socialmente determinados, possibilitados por uma formação ampla e integral. Ciavatta (2014) destaca que,

[...] Do ponto de vista do conceito, formação integrada significa mais do que uma forma de articulação entre ensino médio e educação profissional. Ela busca recuperar, no atual contexto histórico e sob-uma específica de correlação de forças entre as classes, a concepção de educação politécnica, de educação omnilateral e de escola unitária (p. 197).

Para que essa formação se efetive no atual contexto, é imprescindível a realização de práticas pedagógicas dialógicas de ensino que articulem educação e trabalho, teoria e prática, saberes técnicos, científicos e culturais no sentido do desenvolvimento da reflexão, criticidade e evolução para autonomia. Assim, entre as possíveis práticas transformadoras, os projetos integradores se destacam como modelo de desenvolvimento para uma formação integrada. 


\section{PROJETO INTEGRADOR COMO POSSIBILIDADE DE PRÁTICA DIALÓGICA DE ENSINO}

Para Araújo e Frigotto (2015), pensar em uma ação de ensino, que compreenda a dialogicidade do mundo e compromissada com a transformação social é um desafio metodológico e político 'por envolver a organização de práticas de ensino, que sejam capazes de promover nos sujeitos, um amplo desenvolvimento de todas as suas capacidades humanas, no sentido da construção de um mundo fraterno e justo, com homens autônomos e livres. Para tal, o desenvolvimento de práticas com esse compromisso, se faz por meio da cooperação e autonomia, entre docentes e alunos, constituídas no diálogo, onde,

[...] ambos, professores e estudantes, são os sujeitos da prática pedagógica. Se a função do principal do educador é mediar a relação entre cultura elaborada e o educando, dando direção à aprendizagem, este exercício só terá possibilidades de produzir a autonomia discente e o reconhecimento da realidade social se orientada por um projeto político-pedagógico de transformação da realidade (FRIGOTTO, 2015, p. 74).

Assim, as práticas pedagógicas, numa perspectiva dialógica e emancipadora, visam a mudança da realidade e tem o trabalho educativo como ação, de criação de conhecimento, de identidade e de reflexão crítica das contradições para tomada de consciência e ação transformadora, conforme Araújo e Frigotto (2015). Portanto, para os autores, pensar em tais práticas, envolve a problematização das condições materiais de trabalho e da relação pedagógica do professor e aluno na contextualização com a realidade. Nesse contexto a produção dialógica do conhecimento deve ser intencionalmente estruturada pelo professor, já que não ocorre de forma espontânea pelos alunos.

O reconhecimento de práticas dialógicas no universo da educação profissional integrada, tende a servir como fundamento para reafirmar o seu papel não só na promoção de mão-de-obra qualificada para o mercado de trabalho, mas principalmente por entender, que todos são sujeitos históricos, detentores do poder de mudança. Para que a Educação profissional se desenvolva numa perspectiva dialógica, deve pressupor a real e efetiva participação dos alunos, nas mais diferentes situações, por meio de novos métodos e 
estratégias pedagógicas e que superem o "monólogo e a eliminação de uma prática dialógica" (FAZENDA, 2002).

Nessa perspectiva o desenvolvimento de projetos integradores destaca-se como uma opção metodológica potencialmente adequada e aplicável para a concretização de práticas pedagógicas dialógicas no cotidiano. Conforme Santos e Barra (2012, p. 10),

[...] Considera-se o Projeto Integrador como uma estratégia pedagógica, de caráter interdisciplinar, constituída de etapas e fases e como um eixo articulador do currículo (disciplina ou tema), no sentido da integração curricular e da mobilização, realização e aplicação de conhecimentos que contribuam com a formação de uma visão do todo no decorrer do percurso formativo do educando.

Os Projetos Integradores têm etapas e procedimentos que favorecem a interdisciplinaridade, bem como, a promoção de competências e habilidades necessárias à formação profissional e cidadã do educando. Moura (2007, p. 24) aponta, que os projetos integradores.

[...] visam, sobretudo, articular e inter-relacionar os saberes desenvolvidos pelas disciplinas em cada período letivo, contribuir para a construção da autonomia intelectual dos alunos, por meio da pesquisa, assim como formar atitudes de cidadania, de solidariedade e de responsabilidade social. O referido projeto deverá estar vinculado à busca de soluções para as questões locais e regionais, sem perder de vista os contextos nacional e mundial, potencializando o uso das tecnologias com responsabilidade social, sendo, portanto, contextualizado a cada realidade específica.

Na visão de superação entre a dicotomia entre teoria e prática, por meio de uma proposta pedagógica que desenvolva a construção da autonomia da aprendizagem e formação de conhecimento, se constitui, segundo, Santos e Souza $(2017$, p. 4), os projetos integradores, como ação pedagógica. Os autores entendem.

[...] que trabalhar com projetos não significa dissolver o currículo escolar. Ao contrário, este é o ponto de partida para a realização efetiva dos projetos ao longo do processo de ensino e aprendizagem e deve ser sempre entendido como eixo norteador. A concepção de projeto escolar está baseada na ideia de interdisciplinaridade, entendida como diálogo ou 
interação entre duas ou mais disciplinas. Essa proposta de trabalho enfatiza as metodologias ativas, objetiva uma aprendizagem significativa a partir de problemas-eixos.

Para Santos e Souza (2017), a prática pedagógica organizada em projetos, contribui para o desenvolvimento dos alunos, como sujeitos ativos e reflexos, ao promover sua participação ativa nos projetos, possibilitando assim, uma aproximação do processo de produção científica além dos direcionamentos disciplinares. Desta maneira, os projetos para os autores, promovem uma aprendizagem mais significativa, por possibilitar a construção de conhecimento pelos alunos, que atuam de forma, autônoma e reflexiva na realização dos mesmos.

Portanto, essa construção, se constitui com base no enfoque interdisciplinar, que é dialógico, centrado no indivíduo e na sua aprendizagem e na realização coletiva da vida, que se dá inserida em um contexto social. Deste modo, a implementação de projetos integradores aponta, para a construção de competências pelo aluno a partir da realização conjunta do trabalho em equipe, fazendo-se necessário o exercício do diálogo entre os docentes, entre as áreas do conhecimento, entre os alunos e entre professores e alunos, pois, a vida humana se constrói, realiza e transforma na comunicação e coletividade.

Assim, como seres humanos, somos construídos e reconstruídos dentro das relações constituídas no mundo a qual pertencemos. Mundo esse, feito de contradições, lugar de encontros e desencontros, de falas e silêncios, de unidade e divisão, de vida e morte, de liberdade e opressão e de justiça e injustiças, que determinam a existência humana ou não dos sujeitos que o habitam, então, eliminar essas contradições é o caminho para a vida humana, que se faz por meio de uma educação compromissada com um mundo humano, de diálogo, criação e liberdade.

\section{CONSIDERAÇÕES FINAIS}

Este estudo abordou como temática central, as práticas dialógicas de ensino na educação profissional e tecnológica. Pode-se dizer que são insuficientes as pesquisas que procuram tratar dessa temática, voltada para a EPT, apesar disso, os pesquisadores são 
unânimes em concordar que o desenvolvimento de práticas pedagógicas baseadas no diálogo, contribuem para a formação humana, por serem capazes de instigar a curiosidade do aluno que passa a enxergar a realidade de forma mais crítica. Um professor que adota uma postura dialógica, oportuniza aos seus alunos a construírem o seu aprendizado e a sua compreensão com o outro, podendo assim, ensinar e aprender em conjunto no ato de educar e aprender.

Muitas são as possibilidades promissoras de desenvolvimento de práticas pedagógicas dialógicas na EPT, dentre elas, os projetos integradores. O potencial dialógico dos projetos integradores consiste no seu enfoque interdisciplinar, centrado no indivíduo e na sua aprendizagem, que requer uma realização conjunta do trabalho em equipe pautado no exercício do diálogo entre docentes, as áreas do conhecimento e os alunos.

Observou-se ainda que, apesar de se reconhecer a importância do desenvolvimento de práticas pautadas no diálogo, essa não é uma tarefa fácil identificando-se inúmeros desafios que dificultam a sua materialização. Para tanto, se faz necessário que a escola, em especial o docente, reflita criticamente sobre o seu papel e as suas práticas, assumindo uma postura questionadora e democrática na tentativa de romper com os padrões preestabelecidos que permeiam o ideário pedagógico e que dificultam a formação integral do aluno.

Então, pensar e refletir acerca de modelos de ensino que contribuam para uma educação humana que forme sujeitos completos, criativos, autônomos e livres, capazes de construir um mundo de diálogo, fraterno, e que permita a existência plena da vida é um desafio contínuo e vital do mundo humano e da sua própria existência. Todas as questões que trazem a luz essas discussões, são importantes porque buscam construir caminhos possíveis para que esse ideal de existência e evolução da própria humanidade seja uma utopia possível.

Compactuado com um conjunto de homens compromissados com esse ideal de mundo, que se funda também nos ideais da educação transformadora e nos seus modelos de ensino, mediados pelos diálogos no âmbito das relações desenvolvidas no mundo humano, produzimos este capítulo. Pautamos as reflexões na compreensão de educação que entende o homem a partir de sua coletividade, como ser de diálogo, criativo, capaz de pensar, refletir e criar para transformar a si e o seu mundo. O capítulo realça o papel e a 
contribuição das práticas pedagógicas dialógicas configuradas por meio do projeto integrador em contexto da educação profissional e tecnológica.

\section{REFERÊNCIAS}

ALVES, C. M.; DANTAS, A. R. DE P.; SOUZA, F. DAS C. S. Que cidadão devemos formar? Os desafios do ensino de história na educação básica. REVES - Revista Relações Sociais, v. 2, n. 1, p. 119-131, fev. 2019.

ARAÚJO, R. M. L.; FRIGOTTO, G. Práticas pedagógicas e ensino integrado. Revista Educação em Questão, Natal, v. 52, n. 38, p. 61-80, 2015.

CIAVATTA, M. O ensino integrado, a politecnia e a educação omnilateral. Por que lutamos? Trabalho \& Educação, v.23, n.1, p.187-205, jan-abr/2014.

FERNANDES, C. À procura da senha da vida-de-senha a aula dialógica? In: VEIGA, I. P. A. (Org.). Aulas: gênese, dimensões, princípios e práticas. Campinas Papirus, 1999.

FREIRE, P. Educação como prática da liberdade. 30 ed. Rio de Janeiro: Ed. Paz e Terra, 2007. . Extensão ou comunicação? 5 ed. Rio de Janeiro: Paz e Terra, 1980.

. Pedagogia da autonomia: saberes necessários a prática educativa. 15 ed. São Paulo: Paz e Terra, 1996.

. Pedagogia do Oprimido. 17 ed. Rio de Janeiro: Paz e Terra, 1987.

FRIGOTTO, G.; CIAVATTA, M.; RAMOS, M. (Org.). Ensino médio integrado: concepção e contradições. São Paulo: Cortez, 2005.

MOURA, D. H. Ensino médio integrado: subsunção aos interesses do capital ou travessia para a formação humana integral? Educ. Pesqui., v.39, n.3, p.705-720, jul/set 2013.

SANTOS, F. A. Institutos federais: expansão, desafios e diretrizes educacionais. Revista Eletrônica Científica Ensino Interdisciplinar, v. 4, n. 12, p. 739 - 751, nov. 2018.

SANTOS, L. A. S; SOUZA, F. C. S. Projetos integradores: concepções e implementação a luz do PPP do IFRN. Produção do conhecimento em educação profissional: IV Colóquio Nacional e I Colóquio Internacional, Natal, 2017.

SANTOS, M. C. C.; BARRA, S. R. O projeto integrador como ferramenta de construção de habilidades e competências no ensino de engenharia e tecnologia. In: XV CONGRESSO

BRASILEIRO DE EDUCAÇÃO EM ENGENHARIA. Belém, 2012.

SAVIANI, D. O choque teórico da Politecnia. Trabalho, Educação e Saúde. 2003. 
VEIGA, I. P. A. A prática pedagógica do professor de Didática. 2. ed. Campinas, Papirus, 1992. 